\title{
Comparison of Accuracy of Direct Implant Impression Technique using Different Splinting Materials
}

\author{
${ }^{1}$ Sunantha Selvaraj, ${ }^{2}$ Jayashree Mohan, ${ }^{3}$ Paul Simon, ${ }^{4}$ Jayachandran Dorairaj
}

\begin{abstract}
Introduction: The accuracy of an impression remains critical factor in achieving passive fit of an implant framework. The accuracy of the master cast would depend on the type of impression material, the implant impression technique and accuracy of die material. The different impression techniques advocated in the literature for implant impressions include direct (open tray) and indirect (closed tray) techniques. Direct technique use square impression copings that are picked up in the impressions which were used in this study.
\end{abstract}

Objective: To evaluate the accuracy of direct impression made with resin splinted and bis-GMA splinted open-tray impression coping. Thus to compare the accuracy of impressions obtained using different splinting materials.

Materials and Methods: A wax mandibular reference model was fabricated and four implants were placed in the mandibular anterior region using surveyor and acrylized with clear heat cure acrylic resin using injection molding technique. Spaced primary cast was fabricated with a uniform thickness of space about $2 \mathrm{~mm}$. Ten custom trays were fabricated using the light curable resin sheets. Medium body polyether impression material was used. Pentamix was used to get a uniform mix. These trays were randomly divided among the two groups, with five trays in each group. Impression techniques were divided into two groups namely:

Group A-direct impression technique with open tray impression copings splinted with autopolymerizing acrylic resin (GC pattern resin), group B - direct impression technique with open tray impression copings splinted with Protemp TM4 (bisGMA) syringable temporisation material. Thus, final impressions were made. Total of 10 master casts were fabricated. Evaluation of casts using Dynascope-Vision engineering, Tesa Microhite 2D and coordinate measuring machine were used.

Results: Statistical comparisons were made using ANOVA test and post-hoc test. Same amount of deviation values obtained with resin splinted and bis-GMA splinted impression copings.

\footnotetext{
${ }^{1}$ Senior Lecturer, ${ }^{2} \mathrm{Head}$ and Professor, ${ }^{3}$ Professor,

${ }^{4}$ Associate Professor

${ }^{1-3}$ Department of Prosthodontics, Vinayaka Mission's Sankarachariyar Dental College, Salem, Tamil Nadu, India

${ }^{4}$ Department of Periodontics, Vinayaka Mission's Sankarachariyar Dental College, Salem, Tamil Nadu, India

Corresponding Author: Sunantha Selvaraj, Senior Lecturer Department of Prosthodontics, Vinayaka Mission's Sankarachariyar Dental College, Salem, Tamil Nadu, India, Phone: 9994066144 e-mail: drsunujai@yahoo.co.in
}

The difference in the values might be because of the variation in the rigidity of the materials used.

Conclusion: Both the splinting material exhibit similar accuracy in impression, so bis-GMA can be used, which is easy to handle, less time consuming, less technique sensitive, rigid and readily available material in clinics, instead of resin splinted material which is technique sensitive, more time consuming and cumbersome.

Keywords: Direct impression technique, Resin splinted and bis-GMA splinted.

How to cite this article: Selvaraj S, Mohan J, Simon P, Dorairaj J. Comparison of Accuracy of Direct Implant Impression Technique using Different Splinting Materials. Int J Prosthodont Restor Dent 2014;4(3):82-89.

Source of support: Nil

Conflict of interest: None

\section{INTRODUCTION}

The accurate impression making has been emphasized as a significant element in the obtainment of a 'passive fit or optimum fit' between implants and the superstructure. Success in oral rehabilitation is dependent in part, on the accurate registration of those structures that constitute the basis for prosthesis support. An understanding of biomechanics of implant prosthodontics necessitates the fabrication of a passively fitting prosthesis. ${ }^{1}$ An inaccurate impression may result in prosthesis misfit, which can lead to further problems such as mechanical and/or biological complications. ${ }^{2}$ Literature shows that the accuracy of the implant cast depends on many factors: the type of impression material, the implant impression technique, the implant angulation, the die material accuracy and the master cast technique. ${ }^{3}$ Techniques to achieve more accurate impressions for patients with multiple dental implants have been tested.

Among the direct impression techniques, both splinting and nonsplinting have been advocated for accurate impressions. Although splinting with resin, impression plaster or bite registration material has been recommended for maintaining a more accurate interimplant relationship, the accuracy of these techniques in yielding accurate casts is controversial. ${ }^{4-16}$ In order to have rigid and dimensional stable material a newer material bisGMA was used to splint the impression copings. 


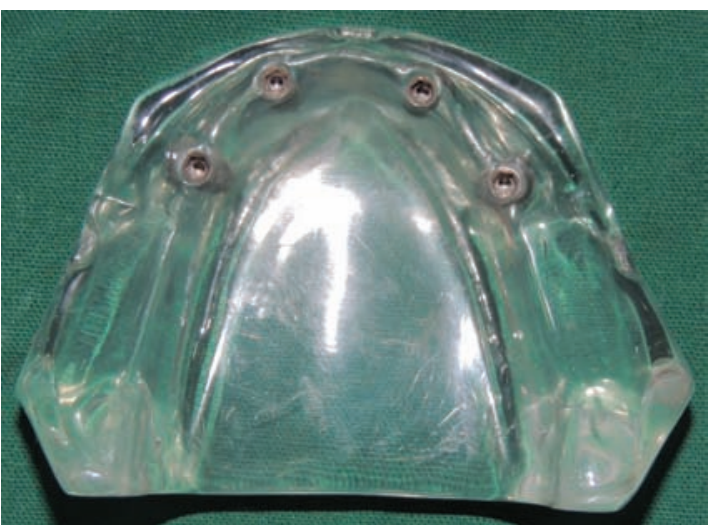

Fig. 1: Finished reference model in heat cure clear acrylic resin

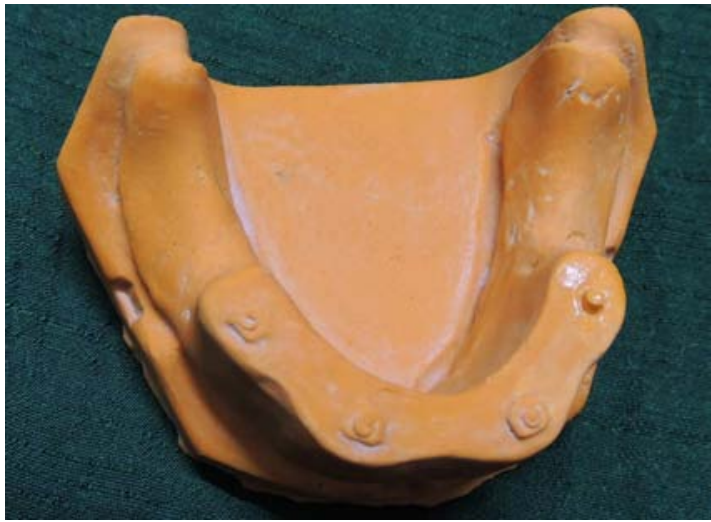

Fig. 3: Spaced primary cast

Paramount importance is to evaluate the accuracy of the impression, in $\mathrm{x}^{-}, \mathrm{y}^{-}$, and $\mathrm{z}$-axis using a reliable measuring system. The purpose of this study was to compare the three dimensional accuracy of casts obtained using a splinting technique with different materials and to evaluate the efficacy of autopolymerizing resin and bis-GMA as splinting materials.

\section{MATERIALS AND METHODS}

A reference model with four implant analogs (Adin Dental Implant System Ltd, Afula, Israel.) in the mandibular symphyseal region was fabricated in clear heat cure acrylic resin (Triplex, Ivoclar, Vivadent) (Fig. 1). The reference model resembled a mandibular implant-supported overdenture situation. Three stops, one in the anterior and two in the posterior region were made in the land area, this ensures the proper orientation of the impression trays. A primary cast was made using indirect impression technique. In order to obtain uniform spacer, $3 \mathrm{~mm}$ even spacer was adapted onto the primary cast (Fig. 2) and the impression made and spaced primary cast was obtained (Fig. 3). Ten custom trays (five per group) with windows in the anterior region were made using light cure acrylic resin sheets Sheet (Plaque Photo, W + P Dental, Hamburg, Germany) of $2 \mathrm{~mm}$ in thickness (Figs 4 and 5). To ensure dimensional stability of custom tray, the trays are left

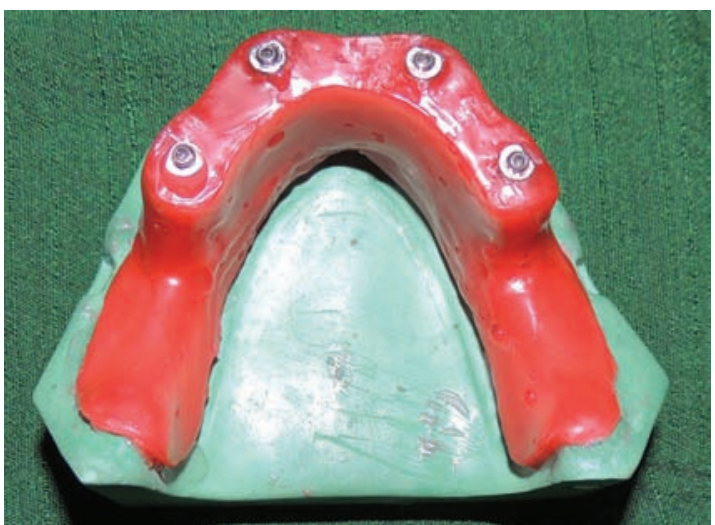

Fig. 2: Spacer adapted to primary cast with impression copings

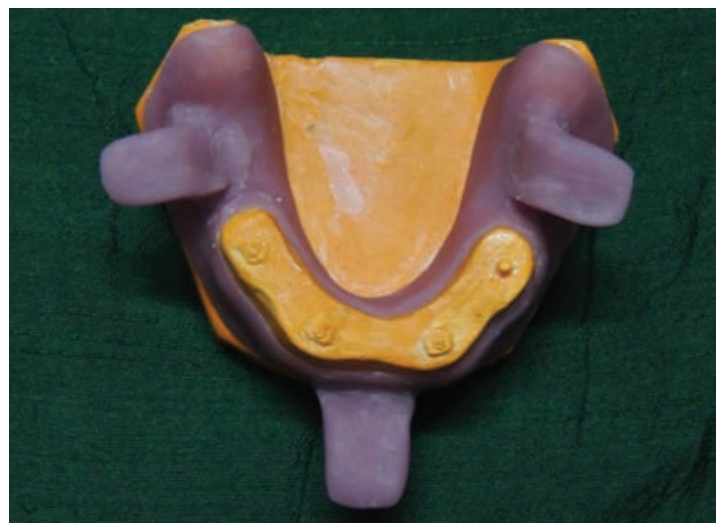

Fig. 4: Resin sheet adapted to the spaced primary cast

undisturbed for 24 hours prior to impression making. The samples were divided into two groups based on impression technique.

- In group $\mathrm{A}$, the open tray impression copings were screwed to the implant body at $15 \mathrm{Ncm}$ torque. The open tray copings where splinted with dental floss (Oral B Waxed Dental Floss, India). Autopolymerizing resin (GC pattern resin, Osaka, Japan) was mixed in the ratio of $2 \mathrm{gm}$ to $1 \mathrm{ml}$. When the resin reached the dough stage, it was packed around the impression posts and the dental floss thus they were splinted together. The splint was allowed to polymerize for 4 minutes. The splint was then sectioned in-between the impression posts using a thin separating disk to relieve the stresses caused due to polymerization shrinkage. The cut sections were joined using the same resin by applying it using brush bead method (Fig. 6). This was again allowed to polymerize for 4 minutes. The impression copings, custom tray and the splint were coated with polyether adhesive and allowed to dry for 15 minutes.

- In group B, the procedure of impression making was similar to group A except that instead of pattern resin, bis-GMA (Protemp 4 3M ESPE, India) was used. The shrinkage of the material is lesser than autopolymerizing resin, so the splints were not sectioned 


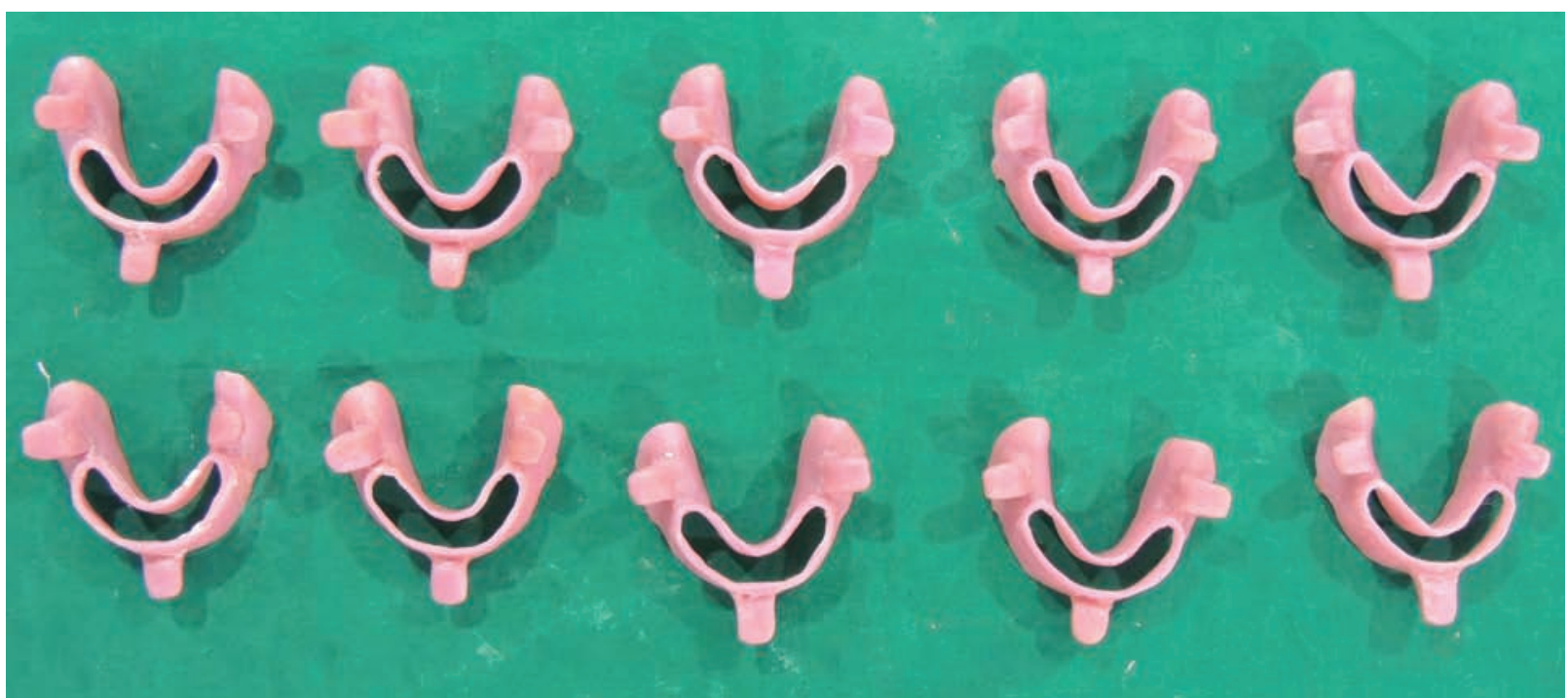

Fig. 5: Finished uniformly spaced custom trays (5 trays per group)

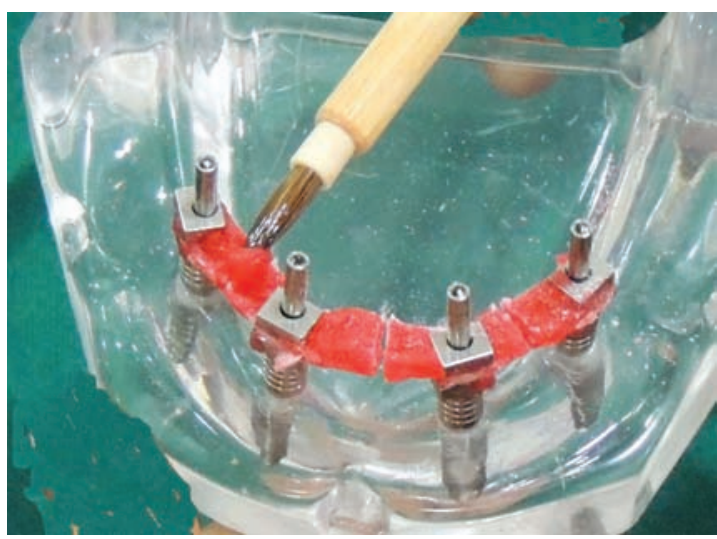

Fig. 6: Reunion of sections by brush bead method

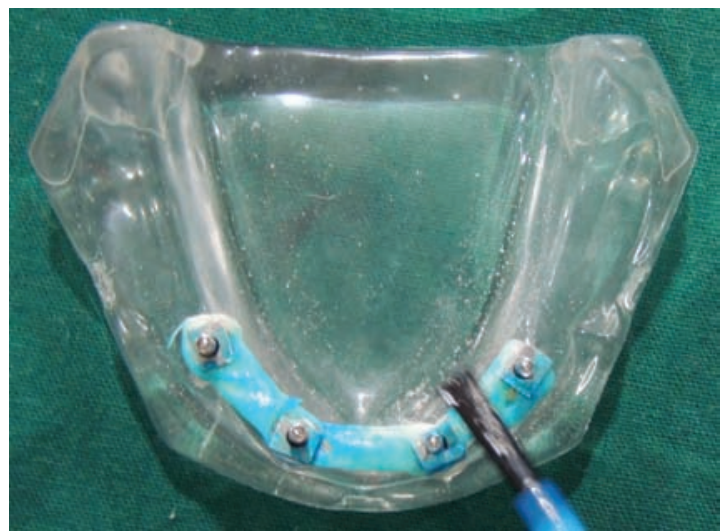

Fig. 8: Application of polyether adhesive

in-between the impression posts. The bis-GMA (Protemp 4 3M ESPE, India) was just syringed using an automix gun (3M ESPE, India) into floss matrix formed between the impression post (Fig. 7). It is allowed to set for about 7 minutes as per the manufacturer's instructions. Once the splinting was rigid then the impression copings, custom tray and the splint were all coated with polyether adhesive (Fig. 8).

The medium body polyether was machine mixed (3M ESPE Pentamix 2, Germany) and dispensed into a penta

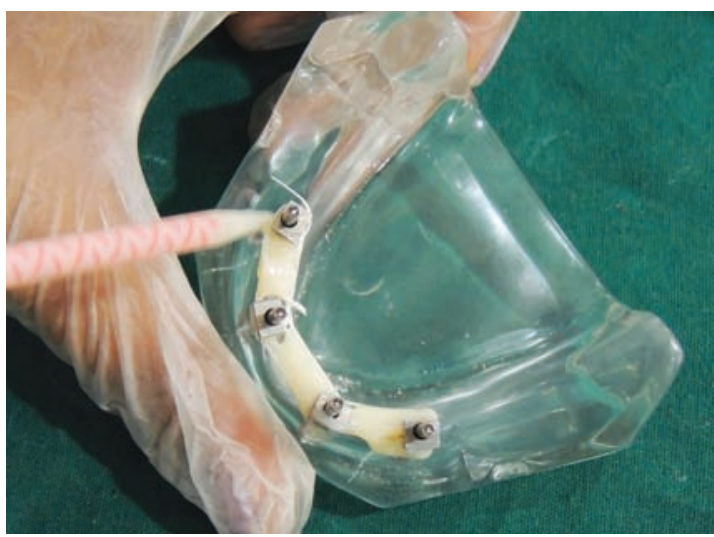

Fig. 7: Syringing bis-GMA temporary crown material

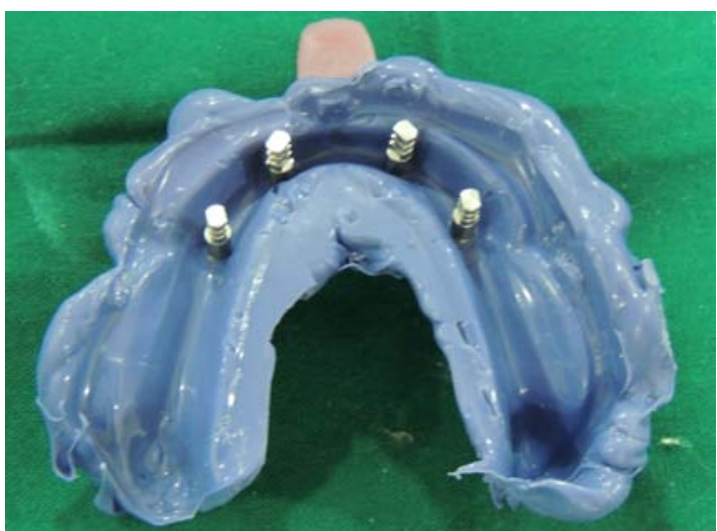

Fig. 9: Completed impression

elastomer syringe (3M ESPE, Germany). It was syringed around the impression copings to avoid impression defects around the copings and loaded in the custom tray. The tray was then carried onto the reference model immediately and the impression made. It was made sure that the tray seated completely in the three stops that were made in the reference model to ensure complete seating and proper positioning of the custom tray. The impression was allowed to set for 6 minutes as per the manufacturer's recommendation. The screws of the impression posts 


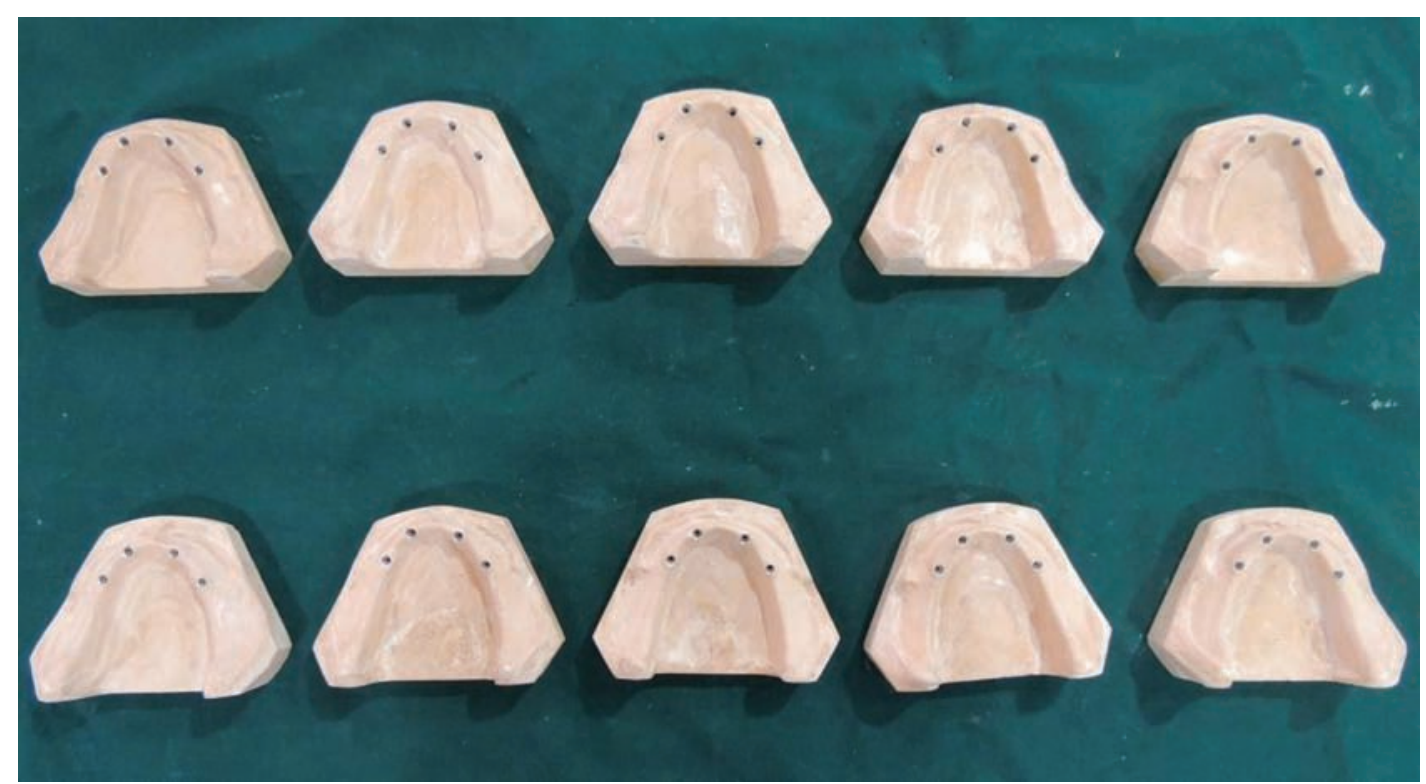

Fig. 10: Finished master casts

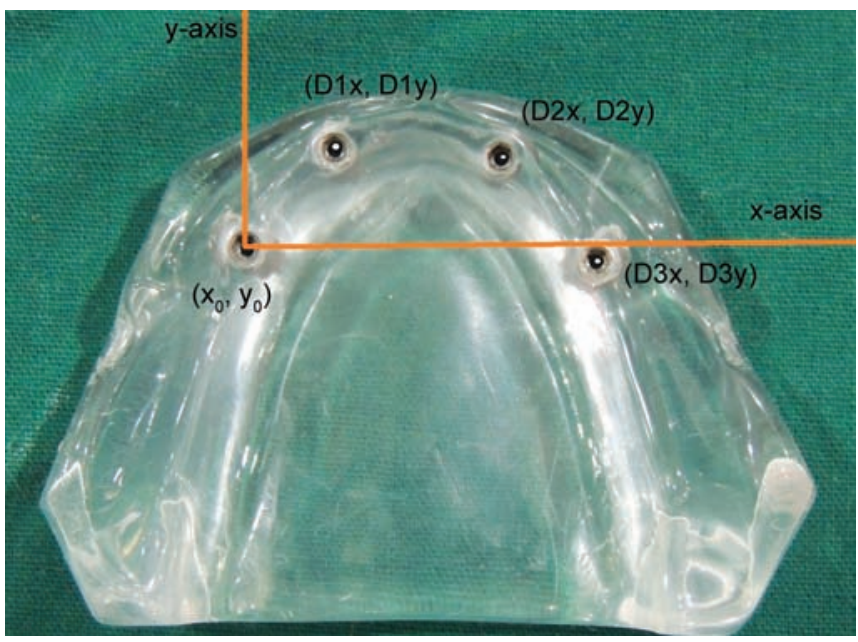

Fig. 11: Inter-implant distances in $x$ - and $y$-axis: D1x and D1y distance between implant/replica 1 and 2 in $x$ - and $y$-axis respectively, D2x and D2y-distance between implant/replica 1 and 3 in $x$ - and $y$-axis respectively, and D $3 x$ and D3y-distance

were unscrewed and the impression removed from the reference model (Fig. 9). A total of five impressions were made in each group in a similar manner. A total of 10 master casts were obtained (Fig. 10), and only one model was obtained from each impression.

\section{MEASUREMENT PROTOCOL}

Dynascope-vision engineering (Tespa Calibration Centre) was used to measure the $x$ - and $y$-axes. The magnified image of each implant and implant replica were visualized in the computer and the external margin of each implant and implant replica was taken as reference point. The coordinates of the center of replica 1 was measured and zeroed and kept as $\left(\mathrm{x}_{0}, \mathrm{y}_{0}\right)$. Keeping this as the reference position the centers of the other 3 replica were determined and the linear distance between the centers of implant/

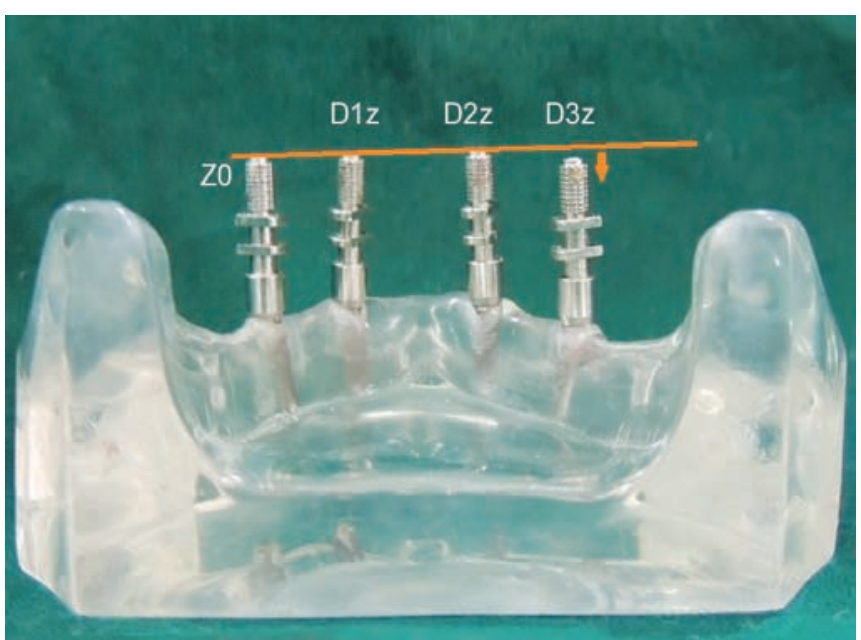

Fig. 12: Inter-implant distances in z-axis: D1z—distance between implant/replica 1 and 2, D2z-distance between implant/replica 1 and 3

replica were all measured in the $\mathrm{X}$ and $\mathrm{Y}$ planes. Thus, the linear distance between the centers of Replica/ implants are 1 and 2 (D1 x/y), 1 and 3 (D2 x/y) and 1 and 4 (D3 x/y) were all measured digitally (Figs 11 and 12).

Tesa Microhite 2D (Tespa Calibration centre) is used to find the planes formed by the platform of implant and replica. The probe was used to measure the plane formed by the platform of implant/replica 1 and it was zeroed. The distance between the plane formed by the implant/ replica platform, 1 and 2 (D1z), 1 and 3 (D2z) and 1 and 3 (D3z) were measured to get the inter-implant distance in the $z$-axis (Fig. 13). The angular relationship between the implant/replica to the base of cast were evaluated using a coordinate measuring machine (CMM-TESA Microhite 3D, TESA Technology). The angle formed between the axis of implant and replica to the base of the model and cast respectively to the horizontal plane. 


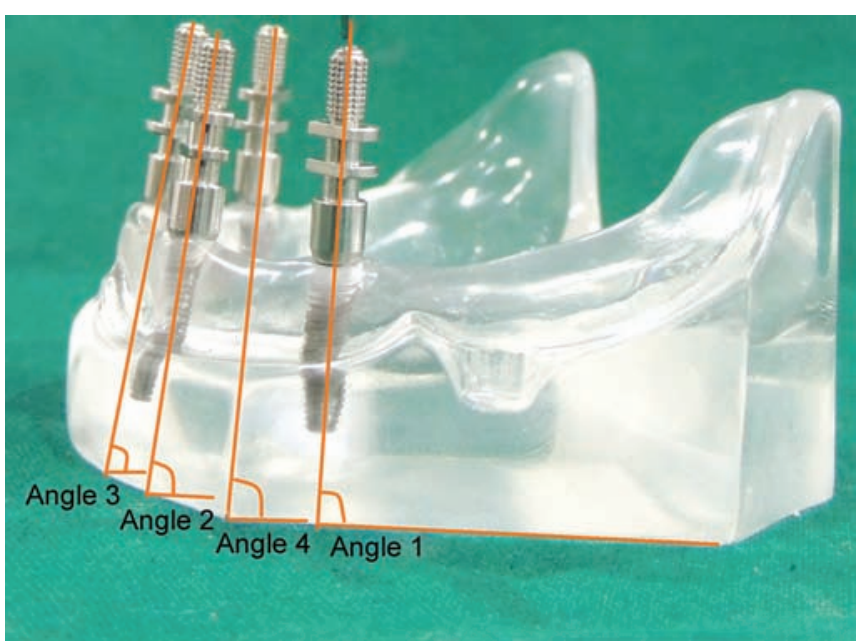

Fig. 13: Angulation of implants to the horizontal plane

The models were measured 5 times for each reading and the mean value was considered. All the measurements were made by a single operator to avoid inter operator error. The measurements were tabulated and they were statistically analyzed and inference was obtained. A factorial analysis of variance using analysis of variance (ANOVA) was used for statistical analysis and $p$-value $<0.05$ was considered as significant. Post-hoc tests-homogeneous subset gives the difference between the groups based on which subset the group falls.

\section{RESULTS}

\section{X-Axis}

The difference in inter-implant distance in $\mathrm{x}$-axis ranged from 116 to $16 \mu \mathrm{m}$ for impressions with resin splinted copings, 33 to $4 \mu \mathrm{m}$ for impressions with bis-GMA splinted copings. The differences in D1x (distance between implant replica 1 and 2), D2x (distance between

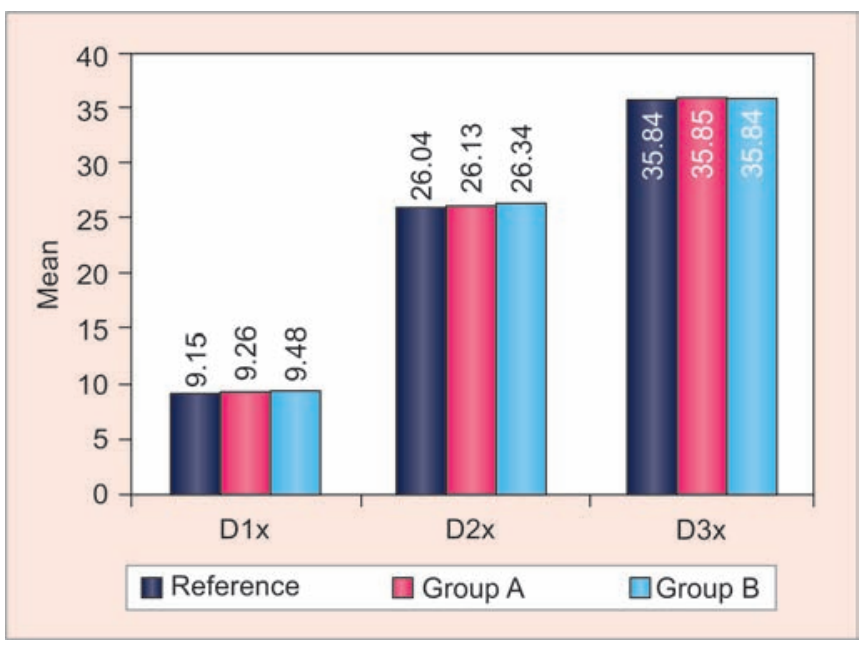

Graph 1: Comparison of inter-implant distance in $\mathrm{x}$-axis (values in $\mathrm{mm}$ ) implant replica 1 and 3) and D3x (distance between implant replica 1 and 4) for both the test groups were not statistically significant when compared with the reference model values (Tables 1, 2 and Graph 1).

\section{Y-Axis}

The difference in inter-implant distance in y-axis ranged from 216 to $180 \mu \mathrm{m}$ for impressions with resin splinted copings, 398 to $926 \mu \mathrm{m}$ for impressions with bis-GMA splinted copings. Maximum differences were seen in D3y (distance between implant replica 1 and 4) values in group B. A similar trend in dimensional distortion was evident in all the groups except that the amount of distortion varied within the groups (Tables 3, 4 and Graph 2).

\section{Z-Axis}

The difference in inter-implant distance in $\mathrm{z}$-axis ranged from 1.1 to $42 \mu \mathrm{m}$ for impressions with resin splinted copings, 1.008 to $-330 \mu \mathrm{m}$ for impressions with bis-GMA splinted copings. The analysis shows that the $p$-value for the D1z, D2z is less than 0.05 and for D3z is greater than 0.05. Post-hoc range tests show that reference group significantly differ with groups A and B as they fall in different subsets. Both the groups A and B showed differences in similar range (Tables 5, 6 and Graph 3).

\section{Implant Angulation in the Z-Axis to the Horizontal Plane}

It plane ranged from -6.78 to -7.21 degrees for the resin splinted group and -3.78 to -5.07 degrees for the bis-GMA splinted group. There was significant difference between the angles $(1,2,3$ and 4$)$ of groups $A$ and $B$ to the reference model (Tables 7, 8 and Graph 4).

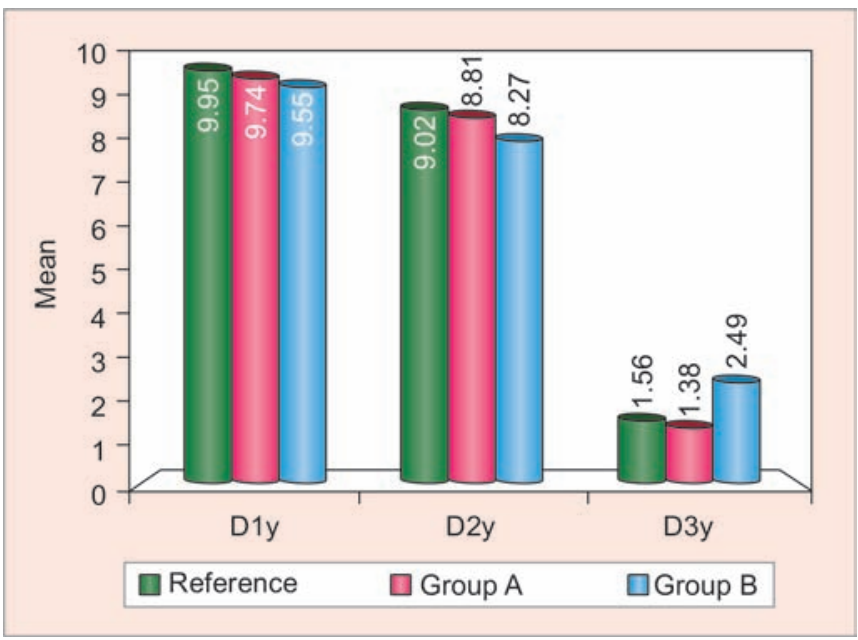

Graph 2: Comparison of inter-implant distance in y-axis (values in $\mathrm{mm}$ ) 


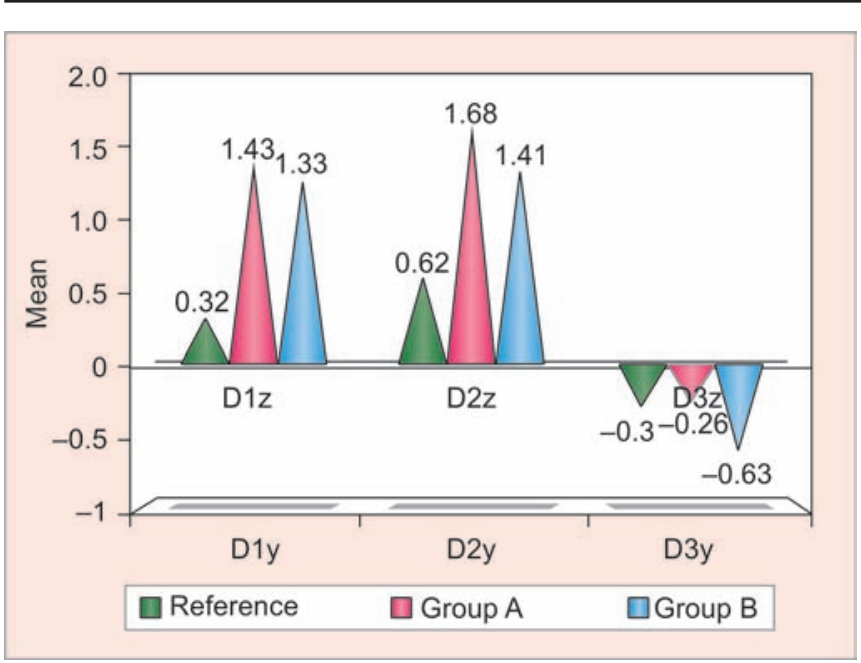

Graph 3: Comparison of inter-implant distance in z-axis (values in $\mathrm{mm}$ )

Table 1: Comparison of inter-implant distance in $\mathrm{x}$-axis (values in $\mathrm{mm}$ )

\begin{tabular}{|c|c|c|c|c|c|c|}
\hline \multirow[t]{2}{*}{ Groups } & \multicolumn{2}{|c|}{$D 1 x$} & \multicolumn{2}{|c|}{$D 2 x$} & \multicolumn{2}{|c|}{$D 3 x$} \\
\hline & Mean & $S D$ & Mean & $S D$ & Mean & $S D$ \\
\hline Reference & 9.15 & 0.00 & 26.04 & 0.00 & 35.84 & 0.00 \\
\hline Group A & 9.26 & 0.34 & 26.13 & 0.36 & 35.85 & 0.13 \\
\hline Group B & 9.48 & 0.07 & 26.34 & 0.06 & 35.84 & 0.13 \\
\hline F statistics & \multicolumn{2}{|c|}{3.52} & \multicolumn{2}{|c|}{2.65} & \multicolumn{2}{|c|}{0.03} \\
\hline$p$-value & \multicolumn{2}{|c|}{0.063} & \multicolumn{2}{|c|}{0.111} & \multicolumn{2}{|c|}{0.970} \\
\hline
\end{tabular}

Table 3: Comparison of inter-implant distance in y-axis (values in $\mathrm{mm}$ )

\begin{tabular}{|c|c|c|c|c|c|c|}
\hline \multirow[t]{2}{*}{ Groups } & \multicolumn{2}{|c|}{ D1y } & \multicolumn{2}{|c|}{$D 2 y$} & \multicolumn{2}{|c|}{ D3y } \\
\hline & Mean & $S D$ & Mean & $S D$ & Mean & $S D$ \\
\hline Reference & 9.95 & 0.00 & 9.02 & 0.00 & 1.56 & 0.00 \\
\hline Group A & 9.74 & 0.32 & 8.81 & 0.47 & 1.38 & 0.58 \\
\hline Group B & 9.55 & 0.12 & 8.27 & 0.24 & 2.49 & 0.21 \\
\hline F statistics & \multicolumn{2}{|c|}{5.04} & \multicolumn{2}{|c|}{7.91} & \multicolumn{2}{|c|}{13.97} \\
\hline$p$-value & \multicolumn{2}{|c|}{$0.026^{*}$} & \multicolumn{2}{|c|}{$0.006^{* \star}$} & \multicolumn{2}{|c|}{$0.001^{\star *}$} \\
\hline
\end{tabular}

*Significant at $5 \%$; ** Significant at $1 \%$

Table 5: Comparison of inter-implant distance in z-axis (values in $\mathrm{mm}$ )

\begin{tabular}{lccllllll}
\hline \multirow{2}{*}{ Groups } & \multicolumn{2}{c}{$D 1 z$} & & \multicolumn{2}{c}{$D 2 z$} & & \multicolumn{2}{c}{$D 3 z$} \\
\cline { 2 - 3 } \cline { 7 - 8 } \cline { 7 - 8 } & Mean & $S D$ & & Mean & $S D$ & & Mean & $S D$ \\
\hline Reference & 0.32 & 0.00 & & 0.62 & 0.00 & & -0.30 & 0.00 \\
Group A & 1.43 & 0.46 & & 1.68 & 0.65 & & -0.26 & 0.51 \\
Group B & 1.33 & 0.13 & & 1.41 & 0.23 & & -0.63 & 0.43 \\
F statistics & 24.53 & & \multicolumn{2}{c}{9.61} & & \multicolumn{2}{c}{1.38} \\
p-value & $<0.001^{* *}$ & & \multicolumn{2}{c}{$0.003^{\star *}$} & & 0.290 \\
\hline
\end{tabular}

*Significant at $5 \%$; **Significant at $1 \%$

\section{DISCUSSION}

The overall accuracy of the impression depends on all the four parameters in the $x, y, z$-axis and anglation of implant/replicas axis to the horizontal plane. The errors in the resin splinting group could be attributed to the minimal shrinkage of the pattern resin used and the technique of splinting. Since the splint was sectioned

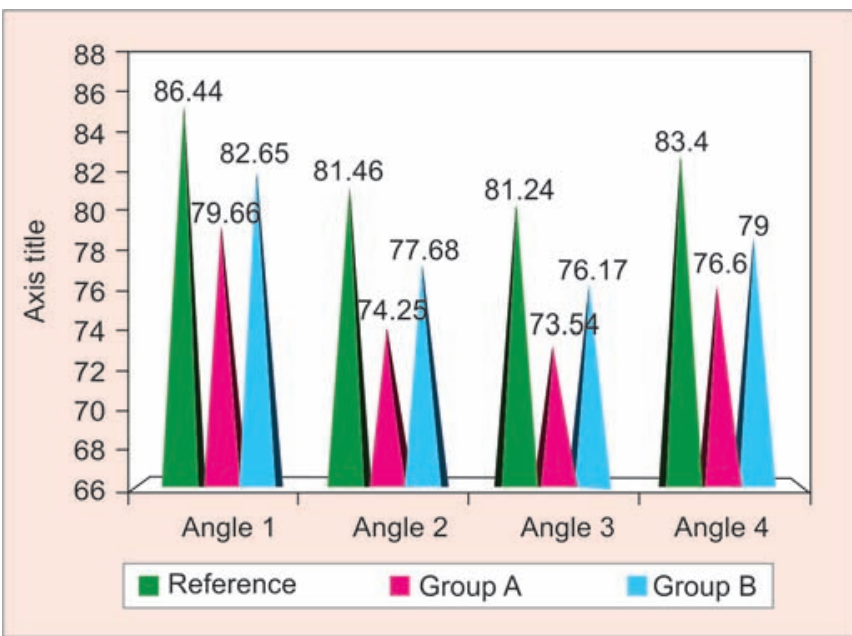

Graph 4: Comparison of implant angulation to horizontal plane in z-axis (in degrees)

Table 2: Difference in inter-implant distance in $\mathrm{x}$-axis (values in $\mathrm{mm}$ )

\begin{tabular}{|c|c|c|c|c|c|c|}
\hline \multirow[t]{2}{*}{ Groups } & \multicolumn{2}{|c|}{$\Delta D 1 x$} & \multicolumn{2}{|c|}{$\Delta D 2 x$} & \multicolumn{2}{|c|}{$\Delta D 3 x$} \\
\hline & Mean & $S D$ & Mean & $S D$ & Mean & $S D$ \\
\hline$A$ & 0.116 & 0.338 & 0.084 & 0.364 & 0.016 & 0.131 \\
\hline$B$ & 0.330 & 0.072 & 0.298 & 0.054 & 0.004 & 0.129 \\
\hline
\end{tabular}

$\Delta \mathrm{D} 1 \mathrm{x}=\mathrm{D} 1 \mathrm{x}$ of the test group $-\mathrm{D} 1 \mathrm{x}$ of the reference model; $\Delta \mathrm{D} 2 \mathrm{x}=$ $D 2 x$ of the test group - D2 $x$ of the reference model; $\Delta D 3 x=D 3 x$ of the test group - D3x of the reference model

Table 4: Difference in inter-implant distance in y-axis (values in $\mathrm{mm}$ )

\begin{tabular}{lllllllll}
\hline Groups & \multicolumn{2}{c}{$\Delta D 1 y$} & & \multicolumn{2}{c}{$\Delta D 2 y$} & & \multicolumn{2}{c}{$\Delta D 3 y$} \\
\cline { 2 - 3 } & Mean & $S D$ & & Mean & $S D$ & & Mean & $S D$ \\
\hline A & -0.210 & 0.323 & -0.216 & 0.475 & & -0.180 & 0.578 \\
B & -0.398 & 0.121 & -0.752 & 0.246 & & 0.926 & 0.208 \\
\hline
\end{tabular}

$\Delta \mathrm{D} 1 \mathrm{y}=\mathrm{D} 1 \mathrm{y}$ of the test group $-\mathrm{D} 1 \mathrm{y}$ of the reference model; $\Delta \mathrm{D} 2 \mathrm{y}=\mathrm{D} 2 \mathrm{y}$ of the test group - D2y of the reference model; $\Delta \mathrm{D} 3 \mathrm{y}=\mathrm{D} 3 \mathrm{y}$ of the test group $-\mathrm{D} 3 \mathrm{y}$ of the reference model

Table 6: Difference in inter-implant distance in z-axis (values in $\mathrm{mm}$ )

\begin{tabular}{|c|c|c|c|c|c|c|}
\hline \multirow[t]{2}{*}{ Groups } & \multicolumn{2}{|c|}{$\Delta D 1 z$} & \multicolumn{2}{|c|}{$\Delta \mathrm{D} 2 \mathrm{z}$} & \multicolumn{2}{|c|}{$\Delta D 3 z$} \\
\hline & Mean & $S D$ & Mean & $S D$ & Mean & $S D$ \\
\hline A & 1.108 & 0.463 & 1.060 & 0.648 & 0.042 & 0.505 \\
\hline B & 1.008 & 0.131 & 0.786 & 0.228 & -0.330 & 0.433 \\
\hline
\end{tabular}

in between the copings and then reunited, it could have minimized the polymerization shrinkage. Therefore, the amount of resin used for initial splinting could have not influenced the inaccuracy, whereas the dimension of the section made could have influenced the accuracy as it was joined again with resin before making impression. ${ }^{17}$ Further research on the dimensions of the splint and the dimensions of the section would shed light on the influence of resin shrinkage on the accuracy of impression. Also, the 
Table 7: Comparison of implant angulation to horizontal plane in z-axis (in degrees)

\begin{tabular}{|c|c|c|c|c|c|c|c|c|}
\hline \multirow[t]{2}{*}{ Groups } & \multicolumn{2}{|c|}{ Angle 1} & \multicolumn{2}{|c|}{ Angle 2} & \multicolumn{2}{|c|}{ Angle 3} & \multicolumn{2}{|c|}{ Angle 4} \\
\hline & Mean & $S D$ & Mean & $S D$ & Mean & $S D$ & Mean & $S D$ \\
\hline Reference & 86.44 & 0.00 & 81.46 & 0.00 & 81.24 & 0.00 & 83.40 & 0.00 \\
\hline Group A & 79.66 & 2.41 & 74.25 & 2.28 & 73.54 & 2.67 & 76.60 & 2.45 \\
\hline Group B & 82.65 & 2.77 & 77.68 & 3.71 & 76.17 & 2.34 & 79.00 & 2.74 \\
\hline F statistics & \multicolumn{2}{|c|}{12.86} & \multicolumn{2}{|c|}{10.30} & \multicolumn{2}{|c|}{18.24} & \multicolumn{2}{|c|}{13.20} \\
\hline p-value & \multicolumn{2}{|c|}{$0.001^{* *}$} & \multicolumn{2}{|c|}{$0.002^{\star *}$} & \multicolumn{2}{|c|}{$<0.001^{\star *}$} & \multicolumn{2}{|c|}{$0.001^{\star *}$} \\
\hline
\end{tabular}

*Significant at $5 \%$; **Significant at $1 \%$

Table 8: Difference in implant angulation to horizontal plane in z-axis (values in degrees)

\begin{tabular}{|c|c|c|c|c|c|c|c|c|}
\hline \multirow[t]{2}{*}{ Groups } & \multicolumn{2}{|c|}{$\Delta$ Angle 1} & \multicolumn{2}{|c|}{$\triangle$ Angle 2} & \multicolumn{2}{|c|}{$\Delta$ Angle 3} & \multicolumn{2}{|c|}{$\Delta$ Angle 4} \\
\hline & Mean & $S D$ & Mean & $S D$ & Mean & $S D$ & Mean & $S D$ \\
\hline A & -6.78 & 2.41 & -7.21 & 2.28 & -7.70 & 2.67 & -6.80 & 2.45 \\
\hline B & -3.79 & 2.77 & -3.78 & 3.71 & -5.07 & 2.34 & -4.40 & 2.74 \\
\hline
\end{tabular}

$\Delta$ Angle $1=$ angle 1 of the test group - angle 1 of the reference model; $\Delta$ Angle $2=$ angle 2 of the test group - angle 2 of the reference model; $\Delta$ Angle $3=$ angle 3 of the test group - angle 3 of the reference model; $\Delta$ Angle $4=$ angle 4 of the test group - angle 4 of the reference model

technique of resin splinting has differed among various studies done so far. ${ }^{18-24}$

Since bis-GMA (Protemp 4) has not been tested for accuracy as a splinting material, data regarding the accuracy of this material for splinting purpose is lacking. Thus the values obtained for this materials in this study have to be compared with the values obtained with the resin splinting group only (since enormous studies had been conducted for the resin splinted copings). The range of differences obtained in bis-GMA splinted group in all the axes were almost in the similar range when compared to the resin splinted group. In $x$-axis, both the groups $\mathrm{A}$ and $B$ exhibits no differences with the reference model. But in $y$ and z-axes and the implant angulation to the horizontal plane, both the groups A and B exhibited significant differences with the reference model in the similar range of difference.

- This preliminary effort to study the accuracy of splinted impression techniques with different splinting materials has yielded positive results especially in relation to the use of bis-GMA (Protemp 4syringable temporary crown material), further research on the use of this material for splinting purpose might be of use to enhance the accuracy of impression techniques. The results obtained in this study are in vitro and so future clinical studies are required to evaluate the effect of intraoral conditions on the materials used for splinting.

\section{CONCLUSION}

The following conclusions were arrived within the limitations of this in vitro study, which evaluated the accuracy of different direct impression techniques for multiple implants.
- On comparison of the accuracy of implant impressions made by direct technique using resin splinted impression copings and bis-GMA splinted impression copings yielded casts closer to the reference model and within the clinical limits.

- Both the splinting material showed same amount of variation from the reference casts and these splinting materials was statistically similar to each other and falls in same homogenous subsets.

- Thus, both the splinting material exhibit similar accuracy in impression, so bis-GMA can be used, which is easy handling, less time consuming, less technique sensitive, readily available material in clinical and more rigid material, instead of resin splinted material which is technique sensitive, more time consuming and more cumbersome.

\section{REFERENCES}

1. Lorenozoni M, Pertl C, Penker K, Polansky R, Sedaj B, Wegscheider WA. Comparison of transfer precision of three different impression materials in combination with transfer caps for the Frialit-2 system. J Oral Rehabil 2000;27:629-638.

2. Goodacre CJ, Bernal G, Rungcharassaeng K, Kan JY. Clinical complications with implants and implant prostheses. J Prosthet Dent 2003;90:121-132.

3. Wee AG. Comparison of impression materials for direct multi-implant impressions. J Prosthet Dent 2000;83:323-331.

4. Adell R, Lekholm U, Rockler B, Branemark PI. A 15-year study of osseointegrated implants in the treatment of the edentulous jaw. Int J Oral Surg 1981;10:387-416.

5. Carr AB. Comparison of impression techniques for a fiveimplant mandibular model. Int J Oral Maxillofac Implants 1991;6:448-455.

6. Liou AD, Nicholls JI, Yuodelis RA, Brudvik JS. Accuracy of replacing three tapered transfer impression copings in two elastomeric impression materials. Int J Prosthodont 1993; 6:377-383. 
7. Branemark PI, Zarb GA, Albrektson T. Tissue-integrated prosthesis: Osseointegration in clinical dentistry in 1985; Publisher: Quintessence.

8. Eames WB, Wallace SW, Suway NB, Rogers LB. Accuracy and dimensional stability of elastomeric impression materials. J Prosth Dent 1979;42:159-162.

9. Humphries RM, Yaman P, Bloem TJ. The accuracy of implant master casts constructed from transfer impressions. Int J Oral Maxillofac Implants 1990;5:331-336.

10. Spector MR, Donovan TE, Nicholls JI. An evaluation of impression techniques for osseointegrated implants. J Prosthet Dent 1990;63:444-447.

11. Carr AB. Comparison of impression techniques for a twoimplant $15^{\circ}$ divergent model. Int J Oral Maxillofac Implants 1992;7:468-475.

12. Vigolo P, Millstein PL. Evaluation of master cast techniques for multiple abutment implant prostheses. Int J Oral Maxillofac Implants 1993;8(4):439-445.

13. Phillips KM, et al. The accuracy of three implant impression techniques: a three-dimensional analysis. Int J Oral Maxillofac Imp 1994;9(5):533-540.

14. Burawi G, Houston F, Byrne D, Claffey N. A comparison of the dimensional accuracy of the splinted and unsplinted impression techniques for the bone-lock implant system. J Prosthet Dent 1997;77:68-75.

15. Vigolo P, Majzoub Z, Cordioli G. Evaluation of the accuracy of three techniques used for multiple implant abutment impressions. J Prosthet Dent 2003;89:186-192.
16. Walker MP, Ries D, Borello B. Implant cast accuracy as a function of impression techniques and impression material viscosity. Int J Oral Maxillofac Implants 2008;23:669-674.

17. Wenz HJ, Hertrampf K. Accuracy of impressions and casts using different implant impression techniques in a multiimplant system with an internal hex connection. Int J Oral Maxillofac Implants 2008;23:39-47.

18. Lee H, Ercoli C, Funkenbusch PD, Feng C. Effect of subgingival depth of implant placement on the dimensional accuracy of the implant impression: an in vitro study. J Prosthet Dent 2008;99:107-113.

19. Lee H, So JS, Hochstedler JL, Ercoli C. The accuracy of implant impressions: a systematic review. J Prosthet Dent 2008b;100: 285-291.

20. Hsu CC, Millstein PL, Stein RS. A comparative analysis of the accuracy of implant transfer techniques. J Prosthet Dent 1993;69:588-593.

21. Assif D, Marshak B, Schmidt A. Accuracy of implant impression techniques. Int J Oral Maxillofac Implants 1996;11:216-222.

22. Vigolo P, Fonzi F, Majzoub Z, Cordioli G. An evaluation of impression techniques for multiple internal connection implant prosthese. J Prosthet Dent 2004;92:470-476.

23. Hariharan R, Chitra S, Manoj R, Miza RB, Azhagarasan NS. Evaluation of accuracy of multiple dental implant impressions using various splinting materials. Int J Oral Maxillofac Implants 2010;25:38-44.

24. Phillips KM, Nicholls JI. The accuracy of three implant impression techniques: a three dimensional analysis. Int J Oral Maxillofac Implants 1994;9:533-540. 